\title{
Efeitos do incremento de fibra dietética sobre a digestibilidade, desempenho e características de carcaça: I. suínos em crescimento e terminação ${ }^{1}$
}

\section{Effects of increasing dietary fiber on digestibility, performance and carcass characteristics: I. growing and finishing gilts}

\author{
Jacinta Diva Ferrugem Gomes ${ }^{2 *}$; Soraia Marques Putrino ${ }^{3}$; Carlos Grossklaus4; \\ Carlos Eduardo Utiyama ; Liliana Lotufo Oetting ${ }^{6}$; Luiz Waldemar de Oliveira \\ Souza $^{7}$; Romualdo Shigueo Fukushima ${ }^{8}$; Antonio Cesar Alves Fagundes ${ }^{8}$; \\ Paulo José do Amaral Sobral ${ }^{9}$; César Gonçalves de Lima ${ }^{10}$
}

\begin{abstract}
Resumo
Objetivando avaliar os efeitos de ração fibrosa sobre parâmetros de digestibilidade dos nutrientes, de desempenho produtivo e de características de carcaça, realizou-se o presente experimento, utilizando 24 suínos mestiços, durante as fases de crescimento e terminação, em delineamento blocos inteiramente casualizados. Os animais foram alimentados à vontade com rações isonutrientes contendo incrementos de 0 ou $8 \%$ de fibra em detergente neutro (FDN), obtidas através da inclusão de 0 ou $10 \%$ de feno de "coast-cross" (Cynodon dactylon). Na fase de crescimento, os tratamentos diferiram para a digestibilidade da matéria seca, energia bruta, proteína bruta e fibra em detergente ácido com piora nos valores para a ração com $8 \%$ de FDN. Na fase de terminação, houve diferença na digestibilidade para matéria seca, energia bruta, proteína bruta, fibra em detergente neutro e fibra em detergente ácido com redução nos índices para a ração com 8\% de FDN. A inclusão de 8\% de FDN não alterou o peso corporal final, ganho de peso, conversão alimentar, rendimentos de carcaças quente e fria, rendimento de carne magra e área de olho de lombo. Os resultados indicaram que o contínuo oferecimento de relativamente baixo teor de FDN alterou a digestibilidade dos componentes dietéticos da ração. Entretanto, como os parâmetros referentes ao desempenho animal e às características de carcaça não foram comprometidos, vislumbrase real possibilidade de emprego de moderadas quantidades de materiais fibrosos na alimentação de suínos, nas fases de crescimento e terminação.

Palavras-chave: Carne magra, feno, fibra em detergente neutro, nutrição, suíno
\end{abstract}

1 Projeto de pesquisa financiado pela Fundação de Amparo à Pesquisa do Estado de São Paulo - FAPESP.

2 Docente do Departamento de Zootecnia da Faculdade de Zootecnia e Engenharia de Alimentos da Universidade de São Paulo FZEA-USP. Av. Duque de Caxias Norte, 225. Jardim Elite, Pirassununga/SP, 13635-900. E-mail: jacintaf@usp.br.

3 Doutora em Zootecnia da FZEA/USP. Zootecnista da Socil Guyomarc'H. somarqputrino@ig.com.br; sputrino@socil.com.br

4 Zootecnista, Gerente de mercado da Socil Guyomarc'H. E-mail: cgrossklaus@ socil.com.br.

5 Doutor em Zootecnia da ESALQ/USP. Zootecnista da NUTRON Alimentos. ceutiyama@yahoo.com; ceutiyama@nutron.com.br lioetting@yahoo.com.

6 Doutora em Zootecnia da ESALQ/USP. Zootecnista da Novus. lioetting@yahoo.com; liliana.oetting@novusint.com

7 Doutor em Reprodução Animal da Faculdade de Medicina Veterinária e Zootecnia - FMVZ-USP. E-mail: wobat@usp.br.

8 Docentes do Departamento de Nutrição e Produção Animal da FMVZ-USP. E- mail: rsfukush@usp.br; acesarf@usp.br.

9 Docente do Departamento de Engenharia de Alimentos da FZEA-USP. E-mail: pjsobral@usp.br.

${ }^{10}$ Docente do Departamento de Ciências Básicas da FZEA-USP. E-mail: cegdlima@usp.br.

* Autor para correspondência

Recebido para publicação 22/03/06 Aprovado em 25/05/07 


\begin{abstract}
This work aimed to evaluate the effects of fibrous ration on parameters of nutrient digestibility, animal performance and carcass characteristics, using 24 crossbred gilts during growing and finishing phases in a completely randomized design experiment. The animals were fed ad libitum with isonutrients rations containing increments of 0 or $8 \%$ neutral detergent fiber (NDF), obtained through the inclusion of 0 or $10 \%$ coast cross grass hay (Cynodon dactylon). In the growing phase, treatments were different for dry matter, energy, crude protein and acid detergent fiber digestibilities with worsening in the valuesfor ration with $8 \% \mathrm{NDF}$. In the finishing phase, differences were detected on digestibility of dry matter, energy, crude protein, neutral detergent fiber and acid detergent fiber with reduction on the rate for the ration with $8 \%$ of NDF. The inclusion of $8 \%$ NDF had no effect upon final body weight, weight gain, feed conversion, yield of hot and chilled carcass, yield of lean meat and loin eye area. The results pointed out that continuous feeding of relatively low content of NDF altered the digestibility of dietary components of the meal. However, as animal performance and carcass characteristics were not compromised, it can be foreseen that moderate quantities of fibrous feedstuff can actually be used for feeding of gilts during the growing and finishing phases.
\end{abstract}

Key words: Hay, lean meat, neutral detergent fiber, nutrition, swine

\section{Introdução}

A carne é um alimento de grande valor biológico para a alimentação humana. Entretanto a sua disponibilidade é, muitas vezes, cerceada pelo seu elevado custo. Desta maneira, deve-se buscar redução do preço para o consumidor final permitindo que, principalmente as classes mais carentes economicamente possam ter acesso a este produto.

A redução do preço da carne para o consumidor final depende enormemente da redução dos custos de produção. As espécies animais não-ruminantes, como suínos e aves, convencionalmente consomem rações majoritariamente baseadas em milho (75-80\% da ração). Este é um insumo de elevado valor já que também é utilizado na alimentação humana. Assim, muitos estudos são realizados para a busca de fontes alimentares alternativas mais baratas para estes animais. As fontes alternativas de alimentos incluem uma grande variedade de subprodutos e resíduos agroindustriais, e as forragens in natura ou conservadas, ricas em fibra dietética.

A possibilidade de se utilizar forragens e outros volumosos como fonte de fibra na produção de suínos não representa um novo conceito, pois já vinha sendo teorizada desde os meados da década de 30 Carroll (POLLMANN; DANIELSON; PEO JÚNIOR, 1979). Entretanto, o estudo sobre o potencial dos diversos alimentos fibrosos sobre a produção suína requer identificação, quantificação e avaliação das interações entre os efeitos fisiológicos e associativos sobre a digestibilidade e desempenho animal, uma vez que estes animais apresentam limitada capacidade do trato digestivo para processar material fibroso. Este tipo de ração pode limitar a produtividade quando fornecida indiscriminadamente a categorias mais jovens, como leitões desmamados ou em fase inicial de crescimento, fêmeas em final de gestação, fêmeas em lactação ou animais debilitados.

O conceito de fibra dietética está diretamente relacionado aos componentes da parede celular vegetal, que são os carboidratos estruturais celulose, hemicelulose e pectina, e a lignina, um composto fenólico (MERTENS, 1992). A celulose, a hemicelulose e a pectina são degradadas a ácidos graxos de cadeia curta através do processo de fermentação no intestino grosso (GOMES; QUEIROZ; FONTES, 1994). Esses ácidos graxos contribuem entre 5 a 30\% das exigências energéticas de manutenção (KENNELLY; AHERNE; SAUER, 1981; RÉRAT et al., 1987).

A susceptibilidade da celulose à hidrólise enzimática microbiana está relacionada à presença de componentes específicos, como a sílica e cutina, além dos fatores intrínsecos da própria fração 
celulose, como por exemplo, a cristalinidade, e certas ligações químicas (ROMAN; HRUSKA, 1987). Ressalte-se também o efeito inibitório da lignina sobre a digestibilidade dos constituintes da parede celular (FUKUSHIMA; DEHORITY, 2000). Para os herbívoros não-ruminantes, a utilização da celulose pelos microrganismos intestinais é altamente prejudicada pelo menor tempo de permanência da digesta no intestino grosso (EHLE et al., 1982). Em conseqüência, geralmente observa-se relação inversa entre a fração de fibra presente na dieta e a digestibilidade da matéria seca (KING; TAVERNER, 1975). Dierick et al. (1989) observaram que esta relação não foi válida para certas fontes de fibra, tais como alfafa, casca de soja, farelo de trigo e polpa de beterraba, provavelmente devido à elevada fermentabilidade destas fontes fibrosas.

A fibra dietética, apesar dessa contribuição energética, pode provocar efeitos deletérios sobre os coeficientes de digestibilidade dos componentes nutritivos (KING; TAVERNER, 1975). Por exemplo, ela pode causar mudanças na taxa de absorção de certos nutrientes, como a proteína, aminoácidos e minerais, e/ou na excreção de nitrogênio endógeno (SCHULZE; VAN LEEUWEN; VERSTEGEN, 1994). Portanto, é imperiosa a adoção criteriosa não só do tipo e/ou qualidade, mas também da quantidade adequada desse alimento para cada categoria animal.

A fração fibra dietética pode ainda afetar a taxa de ingestão alimentar (PEKAS; YEN; POND, 1983; VAREL; POND; YEN, 1984). Pond et al. (1981) concluíram que o oferecimento de ração contendo $35 \%$ de farinha de alfafa, para suínos em crescimento, deprimiu a taxa de ganho de peso e piorou a conversão alimentar; entretanto, promoveu carcaças com menor deposição de gordura subcutânea (espessura de toucinho), condição esta atualmente desejada pelo mercado consumidor.

Segundo Frank, Aherne e Jensen (1983), suínos adultos, como nas fases de terminação e pósterminação, mesmo quando alimentados com elevados níveis de fibra dietética, são capazes de manter ganhos de peso em índices adequados, pela elevação do consumo, como tentativa de manter estável o nível de energia digestível ingerida.

O mercado consumidor apresenta crescente demanda por carne suína com baixo teor de gordura subcutânea que, segundo Gomes (1996), resultou na implantação de um sistema de tipificação de carcaça, onde o produtor é pago pela quantidade e qualidade de seu produto. Assim, carcaças com elevado teor de gordura subcutânea e reduzida quantidade de carne magra recebem valores econômicos inferiores ao de carcaças consideradas "magras".

A adição de fibra dietética na alimentação de suínos nas fases de crescimento, terminação e pósterminação permite melhor controle dos padrões de carcaças, adequando o ganho de peso animal com maior rendimento de carne magra.

Este trabalho objetivou avaliar os efeitos de diferentes níveis de FDN na alimentação sobre a digestibilidade, desempenho zootécnico e características de carcaça de suínos destinados ao abate, nas fases de crescimento e terminação.

\section{Material e Métodos}

A presente pesquisa foi desenvolvida no Setor de Suinocultura, pertencente à Prefeitura do Campus Administrativo de Pirassununga da Universidade de São Paulo, Pirassununga, São Paulo, Brasil.

Foram utilizados 24 suínos mestiços (Landrace e Large White), fêmeas e machos castrados (12 animais/sexo), durante as fases de crescimento e terminação. Na fase de crescimento, os animais apresentaram idades inicial e final de 74 e 110 dias, e pesos inicial e final de 25 e $53 \mathrm{~kg}$, respectivamente. Na fase de terminação, as idades e pesos inicial e final foram de 111 e 146 dias, e 53 e $78 \mathrm{~kg}$, respectivamente.

Os suínos permaneceram em baias individuais, com bebedouro tipo chupeta e comedouro de semigravidade, recebendo água e ração à vontade. A 
alimentação baseou-se em rações experimentais isoprotéicas e isoenergéticas, formuladas de acordo com as exigências para as categorias animais em questão (NATIONAL RESEARCH COUNCIL, 1998) (Tabela 1). A fonte de fibra dietética foi constituída por feno de "coast cross" (Cynodon dactylon), finamente moído. Os tratamentos eram compostos por uma ração testemunha (sem incremento de FDN) e com incremento de $8 \%$ de FDN (obtido por acréscimo de $10 \%$ de feno).

Tabela 1. Composição percentual das rações experimentais contendo incremento de fibra em detergente neutro (FDN)

\begin{tabular}{|c|c|c|c|c|}
\hline \multirow{3}{*}{ Ingredientes, $\%$} & \multicolumn{4}{|c|}{ Fases } \\
\hline & \multicolumn{2}{|c|}{ Crescimento } & \multicolumn{2}{|c|}{ Terminação } \\
\hline & \multicolumn{4}{|c|}{ Incremento de FDN (\%) } \\
\hline & 0 & 8 & 0 & 8 \\
\hline Milho & 80,83 & 65,93 & 86,26 & 72,14 \\
\hline Farelo de soja & 16,00 & 17,44 & 10,70 & 11,89 \\
\hline Feno moído & - & 10,00 & - & 10,00 \\
\hline Óleo de soja & - & 3,71 & - & 3,45 \\
\hline Fosfato bicálcico & 1,82 & 1,80 & 1,38 & 1,35 \\
\hline Calcário calcítico & 0,21 & 0,15 & 0,27 & 0,22 \\
\hline Caulim & 0,16 & - & 0,44 & - \\
\hline Sal & 0,30 & 0,30 & 0,30 & 0,30 \\
\hline Suplemento mineral ${ }^{1}$ & 0,10 & 0,10 & 0,10 & 0,10 \\
\hline Suplemento vitamínico 2 & 0,40 & 0,40 & 0,40 & 0,40 \\
\hline L-Lisina & 0,18 & 0,17 & 0,15 & 0,15 \\
\hline \multicolumn{5}{|c|}{ Composição calculada } \\
\hline Energia digestível, kcal/kg ração & 3.265 & 3.267 & 3.297 & 3.276 \\
\hline Proteína bruta, $\%$ & 14,30 & 14,35 & 12,50 & 12,64 \\
\hline Cálcio, \% & 0,53 & 0,55 & 0,62 & 0,62 \\
\hline Fósforo disponível, \% & 0,53 & 0,55 & 0,50 & 0,49 \\
\hline Lisina & 0,61 & 0,61 & 0,47 & 0,47 \\
\hline Metionina & 0,17 & 0,17 & 0,13 & 0,13 \\
\hline Metionina e Cistina & 0,36 & 0,36 & 0,29 & 0,29 \\
\hline Treonina & 0,37 & 0,37 & 0,30 & 0,30 \\
\hline Triptofano & 0,10 & 0,10 & 0,08 & 0,08 \\
\hline
\end{tabular}

${ }^{1}$ Composição do suplemento mineral por kg de ração: Fe 45 mg; Cu 7,5 mg; Mn 7,5 mg; Zn 65 g; I 42 mg; Co 10 mg. ${ }^{2} \mathrm{Composição}$ do suplemento vitamínico por kg de ração: Vit. A 6500 UI; vit. $\mathrm{D}_{3} 1500 \mathrm{UI}$; vit. E 15 UI; vit. $\mathrm{K}_{3} 2,8$ mg; vit. B 1,5 mg; vit. B 4 $\mathrm{mg}$; vit. $\mathrm{B}_{6} 1,5 \mathrm{mg}$; vit. $\mathrm{B}_{12} 18 \mathrm{mcg}$; ác. nicotínico $20 \mathrm{mg}$; ác. fólico 0,55 mg; ác. pantotênico $15 \mathrm{mg}$; biotina $12 \mathrm{mg}$.

Os manejos sanitário e alimentar foram realizados diariamente. A limpeza era feita através da raspagem das baias, recolhimento e pesagem das sobras.

Para a avaliação do desempenho animal, os dados de peso individual foram coletados no início e final de cada etapa. Os dados de consumo de ração foram obtidos por indivíduo e diariamente, durante todo o período experimental. A conversão alimentar foi calculada a partir dos dados de ingestão total e ganho de peso, no período considerado.

Os ensaios de digestibilidade ocorreram no final das fases de crescimento e terminação. Para a determinação da digestibilidade, adicionou-se óxido crômico $\left(\mathrm{Cr}_{2} \mathrm{O}_{3}\right)$ como marcador externo, na concentração de $0,5 \%$. Os animais passaram por adaptação gradual antes das coletas. Durante o período de coleta de fezes, foi imposta restrição alimentar (80\% do consumo durante o período de adaptação) com o intuito de eliminar possíveis sobras de ração. Foram coletadas $400 \mathrm{~g}$ de fezes por animal no período da manhã e da tarde, sendo as amostras congeladas para posterior análise. O método de coleta foi parcial, seguindo a metodologia preconizada por Moreira (1993). 
As amostras de alimentos, eventuais sobras e fezes de cada animal, dentro de cada período, foram homogeneizadas e colocadas em estufa a $65^{\circ} \mathrm{C}$, durante 72 horas e armazenadas. As amostras foram analisadas para teores de matéria seca, energia bruta, proteína bruta, extrato etéreo, matéria mineral, cálcio, fósforo, fibra em detergente neutro (FDN) e fibra em detergente ácido (FDA). Os teores de FDN e FDA foram determinados seguindo os procedimentos laboratoriais descritos por Van Soest; Robertson e Lewis (1991). As demais análises laboratoriais seguiram as rotinas descritas em ASSOCIATION OF OFFICIAL ANALYTICAL CHEMISTS (1990).

Para a avaliação das características de carcaça dos suínos, os animais foram abatidos no "MatadouroEscola", pertencente à Prefeitura do Campus Administrativo de Pirassununga, Pirassununga-SP, após jejum alimentar e hídrico de 12 horas.

Após todos os procedimentos de abate, evisceração e divisão das carcaças, as meiascarcaças foram pesadas, para obtenção do peso de carcaça quente, e em seguida armazenadas em câmara frigorífica a 3C, para o estabelecimento do rigor mortis. Após 24 horas, as meias-carcaças foram pesadas, para obtenção do peso da carcaça fria, sendo em seguida, registrados os valores de espessura de toucinho entre a $10^{\mathrm{a}}-11^{\mathrm{a}}$ vértebras torácicas, com régua graduada em milímetros. Os rendimentos de carcaça quente e fria foram calculados por divisão dos pesos das carcaças quente e fria, respectivamente, pelo peso vivo dos respectivos animais.

Para o cálculo do rendimento de carne magra, realizou-se a desossa das meias-carcaças direitas. $\mathrm{O}$ rendimento em carne magra foi calculado como a relação entre o peso de carne magra (pernil com osso, carré, paleta sem osso, copa sem osso e aparas magras) e o da carcaça padrão (peso da meia-carcaça menos os pesos da cabeça, papada, pé, rabo e unto).

O delineamento experimental utilizado foi o de blocos inteiramente casualizados, com dois tratamentos ( 0 ou $8 \%$ FDN) e 12 repetições. Os animais foram blocados em função do peso inicial. A análise de variância foi realizada através do procedimento "General Linear Model" do SAS (1992). As médias foram comparadas pelo teste de Tukey $(\mathrm{P}<0,05)$.

\section{Resultados e Discussão}

O oferecimento de $8 \%$ de FDN na ração de suínos durante as fases de crescimento e de terminação, não promoveu diferenças significativas ( $\mathrm{P}>0,05)$ nos parâmetros de desempenho zootécnico: consumo alimentar, ganho de peso e conversão alimentar (Tabela 2).

Tabela 2. Valores de desempenho de suínos alimentados com dietas contendo incrementos de fibra em detergente neutro (FDN), durante as fases de crescimento e de terminação.

\begin{tabular}{|c|c|c|c|c|c|c|}
\hline \multirow{3}{*}{ Parâmetros } & \multicolumn{2}{|c|}{ Incremento FDN, \% } & \multirow[b]{2}{*}{ Média } & \multicolumn{3}{|c|}{ Análise de variância } \\
\hline & 0 & 8 & & $\mathrm{EPM}^{1}$ & $\mathrm{CV} \%^{2}$ & $\mathrm{P}>\mathrm{F}$ \\
\hline & \multicolumn{6}{|c|}{ Fase de crescimento } \\
\hline Peso inicial, $\mathrm{kg}$ & 23,87 & 25,75 & 24,81 & - & - & - \\
\hline Peso final, $\mathrm{kg}$ & 52,30 & 53,04 & 52,67 & 19,656 & 8,42 & 0,687 \\
\hline Consumo diário de ração, $\mathrm{kg}$ & 1,79 & 1,88 & 1,83 & 0,062 & 13,60 & 0,391 \\
\hline Ganho diário de peso, kg & 0,692 & 0,685 & 0,688 & 0,011 & 15,20 & 0,869 \\
\hline \multirow[t]{2}{*}{ Conversão alimentar } & 2,59 & 2,75 & 2,67 & 0,070 & 9,89 & 0,166 \\
\hline & \multicolumn{6}{|c|}{ Fase de terminação } \\
\hline Peso inicial, kg & 52,30 & 53,04 & 52,67 & 19,656 & 8,42 & 0,687 \\
\hline Peso final, $\mathrm{kg}$ & 77,83 & 78,71 & 78,27 & 36,813 & 7,75 & 0,727 \\
\hline Consumo diário de ração, $\mathrm{kg}$ & 2,40 & 2,49 & 2,45 & 0,114 & 13,80 & 0,535 \\
\hline Ganho diário de peso, $\mathrm{kg}$ & 0,709 & 0,713 & 0,711 & 0,011 & 14,88 & 0,932 \\
\hline Conversão alimentar & 3,42 & 3,50 & 3,46 & 0,110 & 9,59 & 0,538 \\
\hline
\end{tabular}

${ }^{1}$ Erro padrão das médias; ${ }^{2}$ Coeficiente de variação. 
Entretanto, Huo (1993) detectou aumento no consumo de matéria seca, possivelmente para equilibrar a diminuição da energia digestível causada pela adição de FDN na forma de casca e farelo de arroz. Segundo Frank, Aherne e Jensen (1983), o suíno, em particular os animais na fase adulta como na terminação e pós-terminação (151-185 dias) mesmo quando alimentado com elevados níveis de fibra dietética, é capaz de manter o ganho de peso em índices adequados devido à sua capacidade de elevação do consumo, como tentativa de manter estável o nível de energia digestível ingerida.

Kass, Van Soest e Pond (1980) não observaram diferença no ganho diário de peso de suínos em crescimento alimentados com ração contendo $26 \%$ FDN (20\% de farinha de alfafa). Similarmente, Chamorro, Sarmiento e Santos (1997) não observaram prejuízos no desempenho geral de suínos em terminação alimentados com ação contendo 15\% de feno de gramínea, mas, Wojcik et al. (1993) registraram melhora no ganho de peso quando o teor de fibra dietética da ração aumentou de 8,2 para $11,9 \%$ (o ganho passou de 0,547 para $0,613 \mathrm{~g} / \mathrm{dia}$ ), possivelmente devido à elevada taxa de fermentação da fibra no intestino grosso.

Contrariamente aos resultados obtidos neste trabalho, algumas pesquisas com suínos durante as fases de crescimento e terminação (DANIELSON; NOONAN, 1975; LUN; SMULDERS; ADEOLA, 1988; HUO, 1993) atribuíram à ração contendo fibra dietética o efeito de reduzir o ganho de peso. Isto pode ser devido à diminuição da digestibilidade dos componentes nutritivos da ração promovido pela presença de polissacarídeos não amiláceos, como afirmaram Etienne (1987), Bell e Keith (1988) e Gomes (1996).

A Tabela 3 apresenta os valores médios dos coeficientes de digestibilidade dos componentes dietéticos das rações de suínos nas fases de crescimento e terminação, alimentados com dieta convencional ou com incremento de FDN. Na fase de crescimento, foram detectadas reduções significativas $(\mathrm{P}<0,01)$ na digestibilidade da matéria seca, energia bruta, proteína bruta e fibra em detergente neutro da ração contendo incremento de $8 \%$ de FDN.

Tabela 3. Coeficientes de digestibilidade das rações experimentais contendo incrementos de fibra em detergente neutro (FDN).

\begin{tabular}{|c|c|c|c|c|c|c|}
\hline \multirow[b]{2}{*}{ Parâmetros } & \multicolumn{2}{|c|}{ Incremento FDN, \% } & \multirow[b]{2}{*}{ Média } & \multicolumn{3}{|c|}{ Análise de variância } \\
\hline & 0 & 8 & & EPM $^{1}$ & $\mathrm{CV} \%{ }^{2}$ & $\mathrm{P}>\mathrm{F}$ \\
\hline & \multicolumn{6}{|c|}{ Fase de crescimento } \\
\hline Matéria seca & $81,90^{\mathrm{a}}$ & $69,09^{b}$ & 75,50 & 19,80 & 5,89 & 0,0001 \\
\hline Energia Bruta & $81,35^{\mathrm{a}}$ & $66,83^{\mathrm{b}}$ & 74,09 & 21,69 & 6,29 & 0,0001 \\
\hline Proteína bruta & $75,80^{\mathrm{a}}$ & $65,68^{\mathrm{b}}$ & 70,74 & 62,34 & 11,16 & 0,0047 \\
\hline Extrato etéreo & 58,79 & 56,60 & 57,69 & 236,01 & 26,63 & 0,7294 \\
\hline Fibra em detergente neutro & 10,46 & 1,78 & 6,12 & 673,02 & 423,72 & 0,4213 \\
\hline \multirow[t]{2}{*}{ Fibra em detergente ácido } & $79,14^{\mathrm{a}}$ & $62,98^{\mathrm{b}}$ & 71,06 & 54,79 & 10,42 & 0,0001 \\
\hline & \multicolumn{6}{|c|}{ Fase de terminação } \\
\hline Matéria seca & $88,28^{\mathrm{a}}$ & $77,79^{b}$ & 83,03 & 4,14 & 2,45 & 0,0001 \\
\hline Energia Bruta & $86,95^{\mathrm{a}}$ & $75,07^{\mathrm{b}}$ & 81,01 & 5,60 & 2,92 & 0,0001 \\
\hline Proteína bruta & $84,73^{\mathrm{a}}$ & $77,46^{\mathrm{b}}$ & 81,10 & 9,74 & 3,85 & 0,0001 \\
\hline Extrato etéreo & 61,72 & 66,64 & 64,18 & 109,51 & 16,30 & 0,2613 \\
\hline Fibra em detergente neutro & $79,28^{\mathrm{a}}$ & $49,23^{\mathrm{b}}$ & 64,26 & 39,16 & 9,74 & 0,0001 \\
\hline Fibra em detergente ácido & $58,51^{\mathrm{a}}$ & $30,71^{\mathrm{b}}$ & 44,61 & 68,05 & 18,49 & 0,0001 \\
\hline
\end{tabular}

${ }^{1}$ Erro padrão das médias; ${ }^{2}$ Coeficiente de variação. Médias seguidas de letras diferentes, na mesma linha, diferem pelo teste de Tukey $(\mathrm{P}<0,001)$.

Contrariamente, Lun, Smulders e Adeola (1988) encontraram valores de digestibilidade similares para matéria seca, energia bruta, energia digestível e energia metabolizável em rações de suínos em crescimento contendo $50 \%$ de triticale em substituição ao milho; entretanto, o aumento do nível 
de fibra dietética foi responsável pelo decréscimo da digestibilidade aparente da proteína, nitrogênio diário absorvido e nitrogênio fecal. Sauer et al. (1991) observaram que dietas fibrosas $(10 \%$ de celulose purificada ou $10 \%$ de palhada de cevada) diminuíram a digestibilidade total do nitrogênio em decorrência da maior síntese de proteína microbiana no intestino grosso e conseqüentemente, aumento da excreção de nitrogênio bacteriano.

Bell e Keith (1988) afirmaram que a adição de $25 \%$ de casca de cevada, utilizada como fonte de fibra na ração de suínos em crescimento, foi responsável pelo aumento da digestibilidade aparente da proteína bruta (de 81,9 para 83,3\%). Contrariamente, em trabalho posterior, Bell e Keith (1989) concluíram que a digestibilidade aparente da proteína bruta foi menor para dietas contendo cevada e sorgo como fonte fibrosa; entretanto, esta diferença na digestibilidade poderia estar associada ao baixo teor de proteína, bem como, ao elevado teor de FDN e tanino destas fontes.

Rodriguez, Boucourt e Riveri (1990), pesquisando rações de suínos contendo 0 ou $13 \%$ de feno de "coast cross", observaram reduções na digestibilidade aparente da matéria seca, matéria orgânica, energia bruta, nitrogênio e fibra bruta.

Para suínos em terminação, o incremento de FDN na ração promoveu redução significativa na digestibilidade da matéria seca, energia bruta, fibra em detergente neutro e fibra em detergente ácido $(\mathrm{P}<0,01)$ (Tabela 3).
O decréscimo da digestibilidade da matéria seca em rações contendo incremento de FDN poderia ser resultante da parcial substituição de uma fonte de carboidrato altamente digestível (amido do milho) por outra fonte de menor digestibilidade como o feno de gramínea, rico em polissacarídeos não amiláceos, que apresentam menor grau de fermentabilidade, ou talvez devido à maior rapidez da taxa de passagem do digesta pelo trato gastrintestinal, fato que reduz a fermentação dos carboidratos estruturais.

É importante elucidar que a habilidade dos suínos em utilizar rações contendo fibra dietética aumenta consideravelmente à medida que o animal se desenvolve, por exemplo, na fase de terminação e na fase adulta, devido ao maior tamanho do trato gastrintestinal, em especial do intestino grosso, e conseqüentemente devido à maior população microbiana (bactérias celulolíticas) encontrada no ceco (VAREL, 1987).

O incremento de FDN na ração não promoveu diferenças significativas $(\mathrm{P}>0,17)$ nos dados referentes às características de carcaça: rendimento de carcaça quente, rendimento de carcaça fria, rendimento de carne magra, área de olho de lombo e espessura de toucinho em suínos em fase final de terminação, alimentados com ração fibrosa durante toda a fase de crescimento-terminação (Tabela 4). Resultados similares foram encontrados por Gomes et al. (1999), muito embora estes autores tenham registrado leve redução nos valores de rendimento de carcaça quente e de espessura de toucinho.

Tabela 4. Parâmetros de carcaça de suínos em terminação alimentados com rações contendo incrementos de fibra em detergente neutro (FDN).

\begin{tabular}{|c|c|c|c|c|c|c|}
\hline \multirow[b]{2}{*}{ Parâmetros } & \multirow{2}{*}{\multicolumn{2}{|c|}{ Incremento de FDN, \% }} & \multirow[b]{2}{*}{ Média } & \multicolumn{3}{|c|}{ Análise estatística } \\
\hline & & & & $\mathrm{EPM}^{1}$ & $\mathrm{CV}^{2}$ & $\mathrm{P}<\mathrm{F}$ \\
\hline Rendimento de carcaça quente, $\%$ & 78,80 & 77,50 & 78,15 & 5,900 & 3,11 & 0,20 \\
\hline Rendimento de carcaça fria, $\%$ & 77,08 & 75,94 & 76,51 & 3,800 & 2,55 & 0,17 \\
\hline Rendimento de carne magra, $\%$ & 40,20 & 40,74 & 40,47 & 0,002 & 6,72 & 0,73 \\
\hline Área de olho de lombo, $\mathrm{cm}^{2}$ & 22,34 & 22,68 & 22,52 & 5,54 & 10,45 & 0,74 \\
\hline Espessura de toucinho, $\mathrm{cm}$ & 2,16 & 1,98 & 2,07 & 0,18 & 20,32 & 0,31 \\
\hline
\end{tabular}

${ }^{1}$ Erro padrão das médias; ${ }^{2}$ Coeficiente de variação. 
Resultados contrários foram encontrados por Pekas, Yen e Pond (1983) e Pond, Jung e Varel (1988), que observaram reduções nos rendimentos de carcaça quente, carcaça fria e espessura de toucinho de suínos em fase de crescimento (alimentados com 50\% de farinha de alfafa) e de terminação (alimentados com $80 \%$ de farinha de alfafa). Entretanto, estes resultados foram provavelmente decorrentes dos elevados níveis de FDN utilizados nas rações dos animais, especialmente nos suínos durante a fase de crescimento. Kass, Van Soest e Pond (1980) reportaram efeitos depressivos em suínos do tipo banha ou carne, durante as fases de crescimento e terminação, somente com altas concentrações de FDN.

Hale e Utley (1985), ao trabalharem com $20 \%$ de casca de soja na alimentação de suínos em crescimento não observaram efeito da fibra sobre o rendimento de carcaça fria.

A redução da espessura de toucinho representa atualmente uma das principais metas determinada pela indústria frigorífica, em especial quando esta redução é acompanhada por uma elevação dos teores de carne magra e área de olho de lombo. A redução da gordura corporal e aumento na quantidade de massa muscular resultam em melhoria da qualidade de carcaça, muito embora seja comum estas características estarem associadas ao menor ganho de peso corporal de suínos alimentados com dietas fibrosas.

Diversos autores observaram redução na espessura de toucinho de suínos alimentados com rações contendo fibra dietética (PEKAS; YEN; POND, 1983) 50\% de farinha de alfafa desidratada para suínos em terminação; (VAREL; POND; YEN, 1984) $24,5 \%$ FDN fornecido por $35 \%$ de farinha de alfafa para suínos em crescimento; (HALE; UTLEY, 1985): 10\% de casca de amendoim para suínos em crescimento; (HALE; NEWTON; HAYDON, 1986) $20 \%$ de casca de soja para suínos em crescimento; (POND et al., 1989) 25\% FDN fornecido por $40 \%$ de farinha de alfafa para suínos em terminação. Embora outros (POND et al., 1981) 26\% FDN para suínos em terminação; (POND; JUNG; VAREL, 1988) $43 \%$ FDN fornecido por $80 \%$ de farinha de alfafa para suínos em terminação; (STAHLY; CROMWELL, 1986) 10\% de farinha de alfafa para suínos em crescimento) não tenham observado nenhum efeito da ração fibrosa sobre esta característica corporal.

\section{Conclusão}

A inclusão de fibra dietética na ração de suínos pode representar uma estratégia alimentar desta espécie monogástrica, uma vez que este componente não provoca alterações deletérias no desempenho e nem prejudica características de carcaça, adequando ganho de peso com rendimento em carne magra.

A utilização de rações para suínos contendo fibra dietética, embora responsável pelo decréscimo da digestibilidade da maioria dos componentes nutritivos, pode representar uma alternativa de substituição ao milho, já que é uma fonte viável de energia. Em algumas situações, este manejo é responsável pelo menor custo de produção.

\section{Referências}

ASSOCIATION OF OFFICIAL ANALYTICAL CHEMISTS .Official methods of analysis. 15.ed. Washington: AOAC, 1990.

BELL, J. M.; KEITH, M. O. Factors affecting the digestibility by pigs of energy and protein in wheat, barley and sorghum diets supplemented with canola meal. Animal Feed Science and Technology, Amsterdam, v.24, n.3-4, p.253-265, 1989.

BELL, M. J.; KEITH, M. O. Effects of barley hulls, dietary protein level and weight of pig on digestibility of canola meal fed to finishing pigs. Canadian Journal Animal Science, Otawa, v.68, n.2, p.493-502, 1988.

CHAMORRO, O.; SARMIENTO, L.; SANTOS, R. Productive performance of finishing pigs feed increasing levels of African star grass (Cynodon nlemfuensis) in the diet. Pig News and Information, London, v.18, p. 143, 1997.

DANIELSON, D. M.; NOONAN, J. J. Roughages in swine gestation. Journal of Animal Science, Savoy, v.41, n.1, p.94-99, 1975. 
DIERICK, N. A.; VERVAEKE, I. J.; DEMEYER, D. I.; DECUYPERE, J. A. Approach to the energetic importance of fiber digestion in pigs. I. Importance of fermentation in the overall energy supply. Animal Feed Science and Technology, Amsterdam, v.23, n.1-3, p.141-167, 1989.

EHLE, F. R.; JERACI, J. L.; ROBERTSON, J. B.; VAN SOEST, P. J. The influence of dietary fiber on digestibility, rate of passage and gastrointestinal fermentation in pigs. Journal of Animal Science, Savoy, v.55, n.5, p.1071-1081, 1982.

ETIENNE, M. Utilization of high fibre and cereal by sow, a review. Livestock Production Science, Amsterdam, v.16, n.3, p.229-241, 1987.

FRANK, G. R.; AHERNE, F. X.; JENSEN, A. H. A study of the relation shop between performance and dietary component digestibilities by swine fed different levels of dietary fiber. Journal of Animal Science, Savoy, v.57, p.645$654,1983$.

FUKUSHIMA, R. S.; DEHORITY, B. A. Feasibility of using lignin isolated from forages by solubilization in acetyl bromide as a standard for lignin analyses. Journal of Animal Science, Savoy, v.78, n.12, p.3135-3143, 2000.

GOMES, J. D. F.; SOBRAL, P. J. A.; LIMA, C. G.; FUKUSHIMA, R. S.; FAGUNDES, A. C. A.; PUTRINO, S. M.; UTIYAMA, C. E.; GROSSKLAUS, C.; OETTING, L. L.; SOUZA, L. W. O. Effects of increasing neutral detergent fiber (NDF) on the performance and carcass characteristics of growing-finishing swine. In: ANNUAL MEETING OF THE AMERICAN SOCIETY OF ANIMAL SCIENCE, 91., 1999, Indianapolis. Anais... Indianapolis: American Society of Animal Science, 1999. v.77, supl.1, p.197.

GOMES, J. D. F. Efeitos do incremento da fibra em detergente neutro, sobre parâmetros de desempenho, de digestibilidade dos componentes dietéticos e da morfologia intestinal de marrãs. 1996. Tese (Doutorado em Zootecnia)- Faculdade de Medicina Veterinária e Zootecnia/Universidade Estadual Paulista, Botucatu.

GOMES, B. V.; QUEIROZ, A. C.; FONTES, C. A. A. Estudo das características físico-químicas de fenos de palhas. II. Efeito sobre a degradabilidade "in situ" da matéria seca, proteína bruta e fibra detergente neutro. Revista da Sociedade Brasileira de Zootecnia, Viçosa, v.23, n.2, p.292-304, 1994.

HALE, O. M.; NEWTON, G. L.; HAYDON, K. D. Effect of diet and exercise on performance, carcass traits and plasma components of growing, finishing barrows. Journal of Animal Science, Savoy, v.62, n.3, p.665-671, 1986.

HALE, O. M.; UTLEY, P. R. Effect of different dietary levels of crude fiber on performance and carcass traits of swine. Nutritional Reports International, Los Altos, v.32, n.4, p.967-971, 1985.
HUO, G. C. Utilization of fibrous materials by the indigenous breed of pigs (Northeast mini pig). 1. Effects of dietary fibre on performance and backfat thickness. Pig News and Information, London, v.14, p.273, 1993.

KASS, M. L.; VAN SOEST, P. J.; POND, W. G. Utilization of dietary fiber from alfafa by growing swine. I. Apparent digestibility of diet components in specific segments of the gastrointestinal tract. Journal of Animal Science, Savoy, v.50, n.1, p.175-191, 1980.

KENNELLY, J. J.; AHERNE, F. X.; SAUER, W. C. Volatile fatty acid prodution in the hindgut of swine. Canadian Journal of Animal Science, Otawa, v.61, n.2, p.349-361, 1981.

KING, R. H.; TAVERNER, M. R. Prediction of the digestible energy in pig diets from analyses of fiber contents. Animal Production, Edimburgh, v.21, p.275-284, Dec. 1975.

LUN, A. K.; SMULDERS, A. H. M.; ADEOLA, O. Digestilibity and acceptability of OAC wintri triticale by growing pigs. Canadian Journal of Animal Science, Otawa, v.68, p.503-510, 1988.

MERTENS, D. R. Análise da fibra e sua utilização na avaliação de alimentos e formulação de rações. In: SIMPÓSIO INTERNACIONAL EM RUMINANTES, 29., 1992, Lavras. Anais... Lavras: Sociedade Brasileira de Zootecnia, 1992. p.188-212.

MOREIRA, I. Valor nutritivo e utilização de milho e soja integral processados a calor na alimentação de leitões. 1993. Tese (Tese em Zootecnia) - Universidade Federal de Viçosa, Viçosa.

NATIONAL RESEARCH COUNCIL. Nutrient requirements of domestic animals. 3.ed. Washington: National Academy Press, 1998.

PEKAS, J. C.; YEN, J. T.; POND, W. G. Gastrointestinal carcass and performance traits of obese versus lean genotype swine: effect of dietary fiber. Nutritional Reports International, Los Altos, v.27, n.2, p.259-270, 1983.

POLLMANN, D. S.; DANIELSON, D. M; PEO JÚNIOR., E. R. Value of high fiber diets for gravid swine. Journal of Animal Science, Savoy, v.48, n.6, p.1385-1393, 1979.

POND, W. G.; YEN, J. T.; LINDVALL, R. N.; HILL, D. Dietary alfalfa meal for genetically obese and lean growing pigs, effect on body weight gain and gastrointestinal tract measurement and blood metabolites. Journal of Animal Science, Savoy, v.51, n.2, p.367-373, 1981.

POND, W. G.; JUNG, H. G.; VAREL, V. H. Effect of dietary fiber on young adult genetically lean, obese and contemporary pigs: body weight, carcass measurements, organ weight and digesta content. Journal of Animal Science, Savoy, v.66, n.3, p.699-706, 1988. 
POND, W. P.; VAREL, V. H.; DICKSON, J. S.; HASCHEK, W. M. Comparative response of swine and rats to highfiber or high-protein diets. Journal of Animal Science, Savoy, v.67, n.3, p.716-723, 1989.

RÉRAT, A.; FISZLEWICZ, M.; GIUSI, A.; VAUGELADE, P. Influence of meal frequency on post-prandial variations in the production and absorption of volatile fatty acids in the digestive tract of conscious pigs. Journal of Animal Science, Savoy, v.64, n.2, p.448-456, 1987.

RODRIGUEZ, N.; BOUCOURT, R.; RIVERI, S. Digestive indicators in pigs consuming high final molasses levels with the addition of fiber. Pig News and Information, London, v.11, p.436, 1990.

ROMAN, L.; HRUSKA, U. S. Thoughts on fiber utilization in swine. Journal of Animal Science, Savoy, v.65, p.497500, 1987.

SAUER, W. C.; MOSENTHIN, R.; AHRENS, F.; HARTOG, L. A. The effect of source of fiber on ileal and fecal amino acid digestibility and bacterial nitrogen excretion in growing pigs. Journal of Animal Science, Savoy, v.69, n.10, p.4070-4077, 1991.
SCHULZE, H.; VANLEEUWEN, P.; VERSTEGEN, M. W. A. Effect of level of dietary neutral detergent fiber on ileal apparent digestibility and ileal nitrogen losses in pigs. Journal of Animal Science, Savoy, v.72, n.9, p.2362-2368, 1994.

STAHLY, T. S.; CROMWELL, G. L. Responses to dietary additions in a cold, warm or hot thermal environment. Journal of Animal Science, Savoy, v.63, n.6, p.1870-1876, 1986.

VAN SOEST,P. J.;ROBERTSON, J. B.;LEWIS, B. A. Methods for dietary fiber, neutral detergent fiber, and nonstarch polysaccharides in relation to animal nutrition. Journal of Dairy Science, Champaign, v.74, p.3583-3597, 1991.

VAREL, V. H. Activity of fiber-degrading microrganisms in the pig large intestin. Journal of Animal Science, Savoy, v.65, n.2, p.488-496, 1987.

VAREL, V. H.; POND, W.G.; YEN, J. T. Influence of dietary fiber on the performance and cellulose activity of growingfinishing swine. Journal of Animal Science, Savoy, v.59, n.2, p.388-393, 1984.

WOJCIK, S.; WIDENSKI, K.; KRÓL, W.; GRELA, E. Effect on fibrous fodder addition to rations on production results of fattening pigs. Pig News and Information, London, v.14,p.173, 1993. 